\title{
Planetary and Extrasolar Insights on the Lower Mantle Source of the Hawaiian, and Other Mantle Plumes
}

\author{
KeITH D. PutirkA ${ }^{1}$
}

${ }^{1}$ Department of Earth \& Environmental Sciences, California State University, Fresno. 2576 E. San Ramon Ave., M/S

ST-24, Fresno, CA 93740. kputirka@csufresno.edu

Estimates of Earth's bulk composition are indefinite to the extent that Earth's lower mantle composition is unknown. Sinking slabs might enrich the lower mantle in pyroxenite (Hofmann and White 1982), and be excavated by plumes. Meanwhile, speculation persists that Earth is chondritic (Bouvier and Bouyet 2016) or contains hidden chondritic components. In a paper, landmark in several respects, Norman and Garcia (1999) note a problem with pyroxenite, e.g., an admixture of $25 \%$ MORB and $75 \%$ Depleted Mantle (DM) would be "hyperfertile". Could hyperfertile materials nonetheless comprise a large fraction of Earth's mantle (Sobolev et al. 2007)? Likewise chondritic mantle domains? Estimates of the silicate portions of Moon, Mars, and Mercury, and interestingly enough, perhaps the nonvolatile fractions of nearby stars, might delimit the possibilities.

McDonough and Sun (1995) showed that Earth is not like any chondrite, and mass balance of major oxides indicates that a hidden component is unlikely to bring Earth to a chondritic (non-volatile Solar) bulk composition. Such a hidden component must comprise nearly a third of Earth's mantle to avoid negative $\mathrm{Ti}$ and $\mathrm{Al}$ contents, and at larger fractions would still be too depleted in $\mathrm{Ca}, \mathrm{Al}$ and $\mathrm{Ti}$ to represent a Hawaiin plume source (Putirka and Rarick 2019). In contrast, a mantle greatly enriched in subducted MORB would be so elevated in $\mathrm{CaO}$ and clinopyroxene as to be a modest anomaly amongst terrestrial planets, and perhaps all exoplanets in our Solar neighborhood (Putirka and Rarick 2019). Rocky planets that precipitate from a Solar-like nebula should equilibrate to a mostly olivine $(\mathrm{Ol})+$ orthopyroxene (Opx) mixture at upper mantle conditions; large variations in $\mathrm{Opx}$ and $\mathrm{Ol}$ are allowable, but large amounts of clinopyroxene are not. If plumes dredge the lower mantle, though, Baffin Island may indicate that pyroxenites are not ubiquitous there. Except for its high ${ }^{3} \mathrm{He} /{ }^{4} \mathrm{He}$ (Jackson et al. 2010) and high mantle potential temperatures (identical to Hawaii; Putirka et al. 2018), Baffin exhumes a quasi-MORBlike depleted source. If all plumes sample a thermally activated region just above the metallic core, then that source is heterogenous, perhaps minor in volume and, in places, highly depleted. And bulk Earth is unique, but not greatly so. 